\title{
Academic Success and Stories of Resiliency: African American Female Students Navigating the College Terrain
}

\author{
Theresa White ${ }^{1, *}$, Paola Nava Jimenez ${ }^{2} \&$ Anna Beatriz Guerrero ${ }^{3}$ \\ ${ }^{1}$ California State University Northridge, United States \\ *Corresponding author: Department of Africana Studies, California State University \\ Northridge, United States. E-mail: theresa.white@csun.edu
}

Received: May 5, 2021 Accepted: May 13, 2021 Published: June 20, 2021

doi:10.5296/ije.v13i2.18602 URL: https://doi.org/10.5296/ije.v13i2.18602

\begin{abstract}
Many educators have become accustomed to using the deficit model of thinking to illustrate the challenges faced by African American students, frequently interpreting their academic struggles as personal failures and lack of resilience. In 2007, a public university in Southern California established the Learning Habits Project (LHP), a study designed to assess the ongoing efforts of university academic programs and to provide data on fostering student success through successful learning habits. This study documented the strategic approaches that foster academic success and resilience employed by 19 African American female college students. Viewed through the lens of Black Feminist Standpoint and Resiliency theories, the results of this study can be used to guide students and educators seeking to improve academic success and resiliency in higher education.
\end{abstract}

Keywords: African American, Black, female, college student, resiliency, standpoint theory 


\section{Introduction}

The My Brother's Keeper initiative, launched by President Barack Obama in 2014, brought much-needed attention to social and cultural factors that impact youth from underrepresented groups. Through this initiative, young men of color have gained support, guidance, and the tools necessary to succeed in life. In order to achieve its goal, the initiative had six important milestones: providing healthy starts for learning, reading at grade level, graduating high school, pursuing post-secondary education, obtaining a job, and maintaining a safe environment. Within two years, the My Brother's Keeper initiative was shown to be effective nationwide, raising over $\$ 600$ million in funding and impacting approximately 250 communities in all 50 states (The White House, 2016a). At present, the initiative continues to seek to close the educational and labor gap for boys and young men of color through the Obama Foundation, (Obama Foundation, n.d.).

Though the My Brother's Keeper initiative focuses on young men of color, the Obama administration also shed light on other underserved student groups. In 2009, The White House Council on Women and Girls was created to propose strategies that break down barriers for young women. In 2016, the council created a report, Advancing Equity for Women and Girls of Color, highlighting female adolescents' and women's lack of support and access to important resources (The White House, 2016b). This paved the way for Prosperity Together, a public-private five-year project launched in 2015 with an investment of 100 million dollars. Recently completed in 2020, it supported women's economic security through education, job training, childcare, and research, carried out by Prosperity Together Partners across the nation (Women's Funding Network, n.d.). While these initiatives continue to afford women of color access to necessary resources to achieve academic success, more data is needed to highlight a model of persistence and success in higher education among African American women.

Launched in the Fall of 2007 at a large public university in Southern California, the Learning Habits Project (LHP) sought to understand newly enrolled students' habits and characteristics by following them across different timelines. This study, which specifically looks into the experience of African American women in a collegiate environment, utilizes secondary data from the project. Nineteen African American female college students, who initially participated in LHP were selected for this study.

\section{Literature Review}

\subsection{Scholar Identity}

The concept of scholar identity encompasses actual academic performance and includes the student's attitudes toward academic achievement and decision-making related to education (Whiting, 2009). In the conceptual model of scholar identity in Black males (Whiting, 2006), self-efficacy beliefs influence traits that are commonly needed for academic achievement. Black male students who have positive self-efficacy beliefs develop high-confidence, resilience, high self-esteem, and self-control (Whiting, 2006), all likely contributors towards 
good academic performance and a positive scholar identity. Additionally, positive scholar identity has been found to have a direct connection with academic success. Students who possess a positive scholar identity tend to exert more effort in their academic pursuits, expand their interactions with peers and faculty, and possess a healthy view of their academic abilities, intelligence, and competence (Whiting, 2006; White \& Lowenthal, 2011). Conversely, students with a negative scholar identity will have more problems at school, are less motivated to work, and therefore more likely to fail (White \& Lowenthal, 2011).

Factors, such as race and gender can have a critical influence on the academic choices that students make throughout their lives (Archer-Banks \& Behar-Horenstein, 2012). Dealing with both racial and gender barriers, Black women are a double minority. They are forced to constantly possess a level of resiliency and power in order to survive and thrive in the face of discrimination (Johnson, 2008) while being imposed by society to maintain a level of self-sufficiency (Brown et al., 2017). As a result, the constant interaction with racial and gender barriers can influence identity development and long-term academic success for African American women. Oftentimes, the results of the inequalities that they experience are considered an individual deficiency rather than a mistake of the institutional system (Winkle-Wagner, 2015). This further adds to their burden when beliefs that they must work hard to obtain a good education are prevalent (Brown et al., 2017). Hannon et al. (2016) argue that while there are benefits to recruiting Black students to predominantly white institutions (PWIs), these academic institutions are still lacking tools that address retention issues for these students. In addition, PWIs potentially hold cultural norms that are influenced by racism and discrimination (Dubois, 2012). An educational environment that supports its students, acknowledges the intersection of their experiences and identities (Porter, 2020), and shows awareness of the societal issues affecting them can contribute to the development of a student's positive scholar identity. In contrast, an unfriendly environment hampers the growth of one's scholar identity (White \& Lowenthal, 2011).

In addition to institutional support, Winkle-Wagner (2015) found that mentorship plays a significant role in African American student's academic success. This is no surprise as mentorship between African American women is an extension of a culture of "sisterhood and motherhood” (Baylor, 2014). In her 2014 study, Aza Baylor, using Patricia Hill Collins' (2009) Black Feminist Theory as a framework, found that "Sankofa, an African proverb meaning "go back to get" and/or "look to the past to inform your future", describes the essence in which...educators received and provided mentoring (p. 109)." According to Johnson (2008), a mentor can be identified as a family member, academic advisor, role model, or peer. In fact, Regina Dixon-Reeves (2003) conducted a study that suggested that African American women are more likely to engage in peer counseling during college, thus mentors can serve as critical non-parental figures. Additionally, spaces that offer dialogue and community building can be avenues for Black women to connect with peers and gain mentorship (Porter, 2020). Providing opportunities for mentorship is one of the many ways in which institutions can help support Black females in the development of a positive academic and scholarly identity.

In essence, academic success cannot be attributed solely to the efforts of the student, as there are several factors that influence a Black female student's scholarly identity. These factors 
include institutional support of intersectional experiences, as well as mentorship and peer relationships. When these factors are integrated into the student's experience, they can develop a positive scholar identity that would foster success in the academic environment.

\subsection{Social and Cultural Identity}

Understanding African American female academic success requires an analysis of their social and cultural identities within, and outside the campus. Fraser, Shane-Simpson, \& Asbell-Clarke (2014) argue that learning is not a completely social nor an individual process, but it acts simultaneously as a combination of both. When developing social identity, belongingness to a certain group or idea is crucial. A sense of belonging among students is also facilitated through social and academic integration (Hausmann, Schofield, \& Woods, 2007). According to Bliuc et al. (2011), students who identified strongly with their discipline of study were more likely to engage in deeper learning and possess positive goals and beliefs on learning. Additionally, academic engagement was further fueled by supportive learning environments (Bliuc et al., 2011), specifically extracurricular activities. These activities play a big role in the development of a student's social identity and social life on campus.

In general, student involvement in extracurricular or co-curricular activities (e.g., clubs and Greek-letter organizations) has been associated with a higher level of campus engagement and increased academic performance (Zacherman \& Foubert, 2014). Research supports the notion that the lack of a support system (largely comprised of peers) is associated with poor college adjustment and a lower GPA than students with a support system (Dennis, Phinney, \& Chuateco, 2006). More specifically, Johnson (2008) emphasizes that "Black Student Unions, Black Awareness Clubs, gospel choirs, and multicultural alliances... [are] critical to sustaining African American students' ability to negotiate their outsider-within status at the schools" (p. 160). At the same time, on-campus communities that provide spaces of affirmation, such as cultural awareness centers, dialogues, and information sessions, allow Black females to thrive in their academic environments (Porter, 2020).

The relationship between collegiate sports and academic success among students has also been explored. African American female student-athletes who exhibited academic success reported lower levels of racial tension, experience less isolation, and overall, have a positive college experience (Moody, 2011). Involvement in on-campus extracurricular activities can also have positive effects on students' mental health, which can influence academic success. In a study by Billingsley \& Hurd (2019), the negative effects of discrimination experienced by minorities enrolled in an elite, predominantly white public university in the U.S were counteracted by involvement in extracurricular activities as it fostered support networks and connections among peers.

The Center for Advanced Research on Language Acquisition (2016) defines culture as the behaviors and interactions individuals learn by socializing with one another. While it cannot be denied that Black culture is beautiful, powerful, and steeped in rich history, it is often viewed negatively by other cultural groups. In multicultural societies, dominant cultures tend to mimic and adopt certain aspects of the less dominant culture (Maycock, 1997). It can be argued that the white community silences the Black community by impersonating and 
adopting certain mannerisms of Black culture. One recent example is "blackfishing", predominantly observed on social media platforms such as Instagram. Torres (2018) defines "blackfishing" as "controversial styling that mimics the skin tone, hair, and aesthetic of many black women, and an unwillingness to be transparent about...non-black heritage" (p. 1). A more prevalent, and often debated example, would be hip-hop. Transcending from its early roots in rap music, hip hop is now a commodity permeating through fashion, lifestyle, and art, creating a multi-billion-dollar industry (Xie et al. (2007). Through hip hop culture, the consumer gets to experience the glamorized parts, without having to understand and go through the circumstances that gave birth to it (Balanda, 2020). Additionally, the commodification of the culture creates another imbalance of power where profits are made from the creative influence of those in a marginalized position (Balanda, 2020). Thus, in the process of appropriation, Black culture becomes distorted and misunderstood, subsequently affecting the identity development of younger Black generations.

Additionally, stereotypes and negative portrayals in the media can affect self-esteem (Brown et al., 2017), making it difficult for Black women to see themselves, and their culture, in a positive light. Hall (2018) argues that many times these negative images are expressed in rap music. Brown et al., (2017) and Hall (2018) reference two consistent images that tend to misrepresent the image of the Black woman: The Sapphire and the Jezebel. The Sapphire represents an aggressive woman who uses manipulation to control men and her household. The Jezebel, on the other hand, represents a liberated sexually aggressive woman who uses sex to get what she wants. Domingue (2015) also described two additional stereotypes: the Black Mama, described as a strong yet self-sacrificing and nurturing figure; and the Exceptional or Educated Black Woman who is perceived to be well-spoken and is more aligned to white standards of behavior, with a powerful and intimidating presence. These images are problematic because they continue to present a negative image of African American women and can encourage members of society to believe them; thus, promoting and maintaining gender and racial oppression towards Black females. This also contributes to microaggressions that African American women continually experience. The persistent stereotypical display of Black women across various media platforms provides yet another obstacle that young Black female students struggle with when developing their cultural identity.

Oftentimes, cultural identity is reinforced through familial relationships and these relationships reinforce how Black women interact with their respective academic environments (Porter, 2020). Thus, family support during college is critical for the success of Black females. In her study, Barnett (2004) found that family support helped Black students decrease their levels of stress. In addition, motivation, help with college applications, parental expectations, and discussion of career choices, between the parents and their children seemed to guide students through their college life (Barnett, 2004). Brown (2017) also writes that family support can help combat negative images through a process of gendered racial socialization, described as "a process by which families provide differing images to African American girls and boys based on their perceptions of the varied racial climate and landscape" (p. 179). Having family support is critical in the development of positive cultural identity, 
therefore enabling Black female students to have a better college experience, which ultimately sets them up for success in academia and beyond.

\section{Theoretical Framework}

\subsection{Black Feminist Standpoint Theory}

Though the Feminist Standpoint Theory has been applied to women as a whole; this study utilizes Black Feminist Standpoint Theory, as outlined by Patricia Hill Collins (2000, 1989). Oftentimes when feminist ideas are being discussed, the majority of representation comes from white, middle-class women, leaving Black women out of the discussion (Collins, 2000). Black Feminist Standpoint theory emphasizes and reflects on the unique, intersectional, experiences of Black women.

Oppression can be experienced in different forms and through different intersecting factors such as race, gender, and class. Collins (2000) defines oppression as an "unjust situation where, systematically and over a long period of time, one group denies another group access to the resources of society" (p. 4). In addition, Collins (2000) mentions several consequences of oppression including negative and controlling images. As Black women resiliently overcome systemic barriers, they gain a unique standpoint on inequality and ways to combat oppression (Collins, 1989). However, despite being part of the same group, individuals can have different interpretations that stem from similar experiences. Additionally, Black Feminist Standpoint Theory acknowledges that Black women are not a monolith and gives voice to individuals within the group. Collins (1989) goes on to say that Black women do not have identical interpretations or experiences regardless of being part of the same group. Black Female Standpoint Theory provides a lens through which individual personal experiences are validated, by critically analyzing the ways in which systemic oppression shape personal narratives.

While Black women have had to show resiliency in the face of multiple oppressions, their unique status also provides them with a distinct point-of-view. This point-of-view is highlighted in the study in order to better understand the relationship between the scholar and social and cultural identities of Black female students, and how it impacts their academic experiences.

\subsection{Resiliency Theory}

Resiliency theory was used as a theoretical framework for this study in order to understand Black female student experiences in navigating academia while having to overcome academic, social, and cultural barriers. Resiliency is defined as the ability to bounce back when confronting adversity (Prince-Embury, 2008). Garmezy (1991) further expands on this theory, exploring three factors of resiliency theory: Individual, Support, and Familial. Individual factors are reflective of temperament indicators and personal qualities such as activity level, intellectual ability or cognitive skills, adaptability to new situations, social responsiveness, and communication skills. Support factors include those outside of familial 
relationships. The qualities of outside support should include strong maternal support, concerned and supportive teachers, or the presence of an institutional structure that connects the child with community support. Familial factors include the presence of a caring adult, despite an absence of responsive parents. Group characteristics that should be present are warmth, cohesion, structure, emotional support, and positive attachment.

This theoretical framework supports the data in the study and will guide the researchers in constructing a narrative of students' experiences in an academic environment and in laying out strategies that promote student success. This study counters previous negative perceptions of Black female experiences that can be a hindrance to academic success.

\section{Method}

The Learning Habits Project (LHP) offered concrete data that presented specific approaches used by 19 African American female students to enhance academic success. In order to participate in LHP, students were required to have a high school GPA of 3.5 or higher and be proficient in English and Math. The project was evaluated by the university's Institutional Review Board (IRB) before implementation. This current study makes use of secondary data obtained from LHP.

Inclusionary criteria specific to this study included enrollment at the public university in Southern California and participation in the Learning Habits Project. Additionally, participants must identify as female and African American. Participants who did not fit the above-mentioned criteria were not included in the study.

Nineteen of the twenty-four African American college students who participated in the LHP were included in the study. Five students from the original cohort were not included, as the information collected during various data points was insufficient to draw substantive conclusions. Demographic data were collected from participants using surveys, as well as semi-structured one-on-one interviews. A majority of participants were interviewed three times $(n=8)$, while six were interviewed twice, and five were interviewed once. During the interviews, they were asked about their study habits, academic challenges, and coping mechanisms when facing barriers related to student success. Information relevant to academic performance, involvement in extracurricular activities, housing, and employment were also collected. The transcribed interviews of each participant were stored on Dedoose, a web application dedicated to qualitative and mixed methods research analysis. The transcriptions from the interviews were then carefully reviewed and coded by researchers into themes.

The data from surveys were explored to assess a range of opinions, attitudes, and values that speak to the participants' strategies and resilience, including study habits and how the participants dealt with academic challenges during the course of their college career. Using the collected data, this study sought to answer the following research questions:

1) What factors influenced the academic success of African American female college students who participated in the Learning Habits Project? 


\section{Macrothink}

2) Are there any academic, societal, and cultural barriers and facilitators that influenced students' academic performance?

3) What specific tools were identified by LHP participants that can be shared across the academic spectrum to promote academic success?

\section{Results}

\subsection{Participants}

With regard to the educational background of the participants' parents (see Table 1), most participants indicated that their parents had taken some college courses $(n=14)$. Six of them indicated some college experience and eight reported a bachelor's degree. The remaining participants $(\mathrm{n}=5)$ stated that their parents had a high school degree or less. Moreover, a majority of the student participants attended a public high school $(n=13)$, while the rest attended a charter/magnet $(n=3)$ or private school $(n=3)$.

Eleven of the 19 participants received the Pell Grant (see Table 2), a financial award commonly given to undergraduate students who show exceptional financial need. On the other hand, a majority of the participants in this sample $(n=14)$ had at least a 3.5 grade point average (GPA) in high school and eleven of the 19 participants scored above average on the SAT (i.e., 1000 or higher). Lastly, 13 of the 19 participants were considered "fully proficient" based on their college entrance exams.

Table 1. Participant and Parental Educational Background

\begin{tabular}{ll}
\hline Description & Number of Participants $(\mathrm{n}=19)$ \\
\hline Parent Educational Background & 5 \\
Highschool Graduate & 8 \\
Attended Some College & 6 \\
Possess a Bachelor's Degree & 13 \\
Participant Educational Background & 3 \\
Attended a public high school & 3 \\
Attended a charter/magnet school & \\
Attended a private school & 14 \\
& 5 \\
Highschool GPA at least 3.5 & \\
Highschool GPA below 3.5 & \\
\hline
\end{tabular}

Note. This table details the educational background of both the participants and their parents. Additionally, this table shows the participants' educational background prior to attending university. 


\section{Macrothink

The participants' educational performance and social activities in college were assessed between two-time points: participants' first and final year at the public university (see Table 2). Twelve of the 19 participants had at least a GPA of 2.5, while seven had lower than a 2.5 in their first year. In their senior year, 13 of the 19 participants had at least a GPA of 2.5, while six had a GPA lower than a 2.5. Finally, ten of the participants indicated that they were involved in extracurricular activities, while nine reported non-involvement. Over the course of the study, several factors changed. The number of participants involved in extracurricular activities decreased across the two time points. Freshman year was the period when most participants $(\mathrm{n}=10)$ were involved in extracurricular activities. In contrast, only four participants indicated involvement in extracurricular activities during the final time point.

Table 2. Participants' Educational and Social Activities in College

\begin{tabular}{ll}
\hline Description & Number of Participants $(\mathrm{n}=19)$ \\
\hline Grade Point Average (GPA) & 12 \\
$1^{\text {st }}$ year: GPA of at least 2.5 & 7 \\
$1^{\text {st }}$ year: GPA of below 2.5 & 13 \\
$4^{\text {th }}$ year: GPA of at least 2.5 & 6 \\
$4^{\text {th }}$ year: GPA below 2.5 & \\
Pell Grants & 11 \\
Pell Grant recipient & 8 \\
Not a Pell Grant recipient & \\
Extracurricular Activities & 10 \\
$1^{\text {st }}$ year: Involved in extracurricular activities & 9 \\
$1^{\text {st }}$ year: Not involved in extracurricular activities & 4 \\
$4^{\text {th }}$ year: Involved in extracurricular activities & 15 \\
$4^{\text {th }}$ year: Involved in extracurricular activities & \\
Housing & 14 \\
$1^{\text {st }}$ year: On-campus & 5 \\
$1^{\text {st }}$ year: Off-campus & 1 \\
$4^{\text {th }}$ year: On-campus & 18 \\
$4^{\text {th }}$ year: Off-campus & \\
Employment & 6 \\
$1^{\text {st }}$ year: Employed & 13 \\
$1^{\text {st }}$ year: Unemployed & 2 \\
$4^{\text {th }}$ year: Employed & \\
$4^{\text {th }}$ year: Unemployed & \\
\hline &
\end{tabular}

Note. This table displays information on the participants' academic and social activities within two time points, freshman year and senior year, while enrolled in the university. 
Most participants $(n=14)$ lived on campus during their freshman year (see Table 2). By the third time point however, only one lived on campus. The number of participants living on campus from the first time point to the last time point decreased significantly. The opposite is the case for employment. The number of participants who were unemployed decreased across both time points. Thirteen participants were unemployed during the first-time point; and by the final time point, only two participants indicated that they were unemployed.

\subsection{Themes}

Transcripts from the interviews were organized into two salient themes: scholar identity, and social and cultural identity. The theme of scholar identity consisted of participants' study strategies and habits, as well as institutional academic supports. Study strategies and habits were further divided into different categories. On the other hand, social and cultural identity involved collegiate extracurricular activities, relationships with students and professors, family support, and role models.

\subsubsection{Scholar Identity}

The students' detailed their study strategies, as well as a freshman introductory seminar course, UNIV 100, as major contributors to the development of their scholar identity and academic success. Academic strategies and supports consisted of the following: flashcards, study groups, study environment, material review, and calendars and personal planners.

Flashcards were one of the most common strategies used by the students. They reported using flashcards in "classes where it's based on knowing definitions, then I [students]... use repetition for those." Students also indicated that the use of flashcards enabled them to have repeated interactions with the material being studied, as they have to read and identify important concepts when creating them. They then proceed to properly review the material written on the flashcards. Students mentioned that this constant repetition helped them memorize important concepts.

Study groups were identified by the participants as another strategy. Students that make use of these group sessions reported that it is a very helpful technique, explaining that "we exchange notes and quiz each other." However, study groups may not be beneficial for all classes, as described by one student, "We studied a lot because it was just a certain group of people so we would study a lot together. For my other classes, I'd usually study by myself or with one other person." Additionally, students indicated that through discussions within the group, they "have the input of what others think, the same as basically the class discussion." Lastly, students valued the relationships they created among their peers through study groups. The importance of support developed from studying within a group, was also emphasized by one student, stating that "if I have a weakness somebody else might have a strength in what I'm weak at."

A conducive study environment/location was also identified by the students as a contributor towards scholar identity formation and academic success. One student described, "going to the library is actually more helpful than staying at the house." While some students made use of the library, others stated their preferences for alternative study areas. For example, a 
student expressed that the library didn't offer enough "stimulation" and it made her feel "anxious." Coffeehouses were described as great places for studying, according to one student. In the interview she described her typical study schedule, stating that she goes to "a coffeehouse or somewhere and stays there for a few hours." She then goes home to "look over everything."

Students also indicated the importance of reviewing course material before class. Students stated that re-reading before class made it easier to understand the professor. Students also noted that it was helpful to print out the PowerPoint slides or other available notes before class so they can "just listen" and not "have to write all the notes down." Calendars and personal planners were also common among students. Students indicated that calendars and planners helped them remain organized and aware of upcoming deadlines. A student mentioned that she "wrote every single test date" in her planner and made sure she gave herself enough time to study.

Lastly, participants reported their appreciation for the university's introductory course, UNIV 100. The university catalog describes the freshman course as "an introduction for the first-time freshmen to the university as an institution, a culture, and an intellectual experience. Academic success is the central goal of the course." Through this course, students are taught practical skills relevant to higher education such as note-taking, test-taking, and critical thinking. Students indicated that the course helped them "learn more about themselves."

\subsubsection{Social and Cultural Identity}

Students also identified various factors that helped form their social and cultural identity. On-campus activities and relationships with professors, as well as relationships outside of the university were listed by the participants as important contributors to their social and cultural identity. Activities identified by participants include clubs and organizations, as well as sports. Several students served as leaders in on-campus organizations such as Greek letter organizations, Associated Students (AS), and the National Association of Black Journalists (NABJ). One student expressed that her involvement in one club has led her to join other clubs, describing that she "started with the BSU [Black Student Union], but they haven't been doing too much lately. I volunteered with United We Stand, have you heard of them?" A student also mentioned that getting involved in a Greek letter organization provided academic benefits in the form of study partners. She went on to describe, "A lot of my study partners are in that fraternity." On the other hand, a student active in sports-based collegiate activities expressed that running track "helps me stay focused because...track makes me have to do my work on time... [in order to] get enough sleep and food." However, it appears that joining on-campus clubs and organizations primarily enrich the university experience. One student stated that joining an on-campus club "helps broaden things for yourself even more... You get to meet and learn more about people." Another student expanded on this and expressed, "I think involvement on campus definitely helps shape your learning... because [university] is so diverse and you get to meet all those different cultures and backgrounds, kind of see how they see things and just learn how to interact."

Students also expressed the importance of building a solid relationship with professors. These 
relationships were critical to learning, with a participant describing, "if things come up and I explain it to them, they are pretty nice about helping me get back on track if I'm behind." Also, professors can serve as mentors and guides. One student expressed, "I have three professors that I have met my freshman year... They still mentor me, and I still have contact with them." Interestingly, one participant provided helpful advice directed to her fellow students during the interview. She went on and said, "Office hours are wonderful. Let your teacher know who you are. Don't just sit in the back of the class and not participate."

Family support and role models within the community were identified by students as important contributors to social and cultural identity. While these are outside of the university, these relationships were highlighted by students as an important source of support and inspiration. However, parental or familial expectations can also add pressure to finish their education. A student confirmed the importance of family support by stating that her parents "are always encouraging [her] to do the best [she] can" and reiterated that "family does play a big part." Several students also expressed that their family expects that they finish college. One student detailed, "My parents and my sister went to college." She also confirmed when the interviewer responded with, "So you're just following along in the expected path." This is further described in detail by one student, in which she said "It's really good to actually have a mother and a father and a grandmother and everybody that is just like, 'you need to go to class, you need to do this, you need to do that'... I also don't have the added pressure of, you know, having to compete...my mom has a master's degree." Regarding the importance of role models, one student mentioned that she came from a disadvantaged neighborhood and she noticed that, "a lot of kids... look up to people that are in college. They say, 'I want to be like you'...I am a model [to] them." However, most of the role models the students mentioned are members of their family. One student looked up to her sister and stated, "My older sister went to college, she got a master's [degree] and the whole works. So she really pushes me to be like her. And, it's not hard trying to live up to her standards, but I try." Another mentioned her parents when she stated, "It is a very positive influence because my parents have done so much in the academic field. My dad was an engineer for 25 years and my mom was a doctor for 20 years and stuff like that."

\section{Discussion}

In this study, African American female students were followed during two important timelines in their college life---their freshman year and senior year. Based on the GPAs collected in the students' freshman and senior year, it can be concluded that the students generally showed consistency in their academic performance. Little change has been observed in the number of participants who had at least a 2.5 GPA in their first and final year in college. Their success in achieving an above average GPA may be related to their perception of their scholar identity (Whiting, 2006; White \& Lowenthal, 2011). This can be further bolstered by feelings of self-efficacy (Whiting, 2006) derived from their previous educational experiences, such as good performance on the SATs and above-average high school grades. Additionally, social and cultural factors may have boosted their academic 
performance, as a majority of these students' parents had some level of college experience, thus their parents' educational experience could have provided students a concrete pathway to academic success (Barnett, 2004).

While the literature (Zacherman \& Foubert, 2014; Moody, 2011; Billingsley \& Hurd, 2019) mentions a positive relationship between extracurricular activities and academic success, it may be worth noting that the students' involvement in extracurricular activities decreased across the two time points. Freshman year was considered the year that most students $(n=10)$ were involved in extracurricular activities. This number, however, significantly decreased throughout their stay in the university. Despite a lower level of extracurricular involvement among student participants during the senior year, the students' GPAs remained fairly the same. While the students have identified specific benefits from engaging in extracurricular activities, such as time management and mental health benefits (Billingsley \& Hurd, 2019), other personal and external factors such as employment and housing may have contributed to a decrease in their involvement in on-campus extracurricular activities. During their freshman year, most students were unemployed $(n=13)$ during the first time point, and in their senior year, only two were unemployed. The time students had previously allotted toward extracurricular activities may have been re-directed into their current jobs. Furthermore, students' housing arrangements could have significantly affected their involvement in extracurricular activities. During the first year, 14 participants lived on-campus, however during their last year, only one remained in on-campus housing. Being housed on campus allows students to have more access to campus resources, including extracurricular activities.

Looking closely at themes that arose from the interviews with the students, the majority of the study strategies for academic success identified by the students can be primarily attributed to their own individual efforts. The use of flashcards, organizing a study group, choosing a conducive study location, reviewing course materials prior to class, and the use of planners/calendars all emphasize the students' diligence in their pursuit towards academic success. This is well-aligned with the common perception among Black women that they need to be independent and self-sufficient (Brown et al., 2017). However, this also adds to the pre-existing notion that they must work twice as hard for a good education (Brown et al., 2017) which creates an additional burden for them. Navigating these academic spaces already places unnecessary pressure on African American women due to existing stereotypes (i.e., Jezebel, Sapphire, and the Exceptionally Educated Black Woman) added to the expectation that they must be self-sufficient, independent, and diligent. While participants identified relationships with professors as an important contributor to academic success, creating and building those relationships can place an additional emotional burden among some students. For instance, students who are already falling behind on their academic performance may be hesitant to ask their professors for help, and instead place extra pressure upon themselves to seek solutions. On the other hand, the mention of the UNIV 100 class shows that students can thrive when provided with a clear pathway on how to achieve their academic goals. The success of this approach can be further improved by teaching strategies geared toward academic success that are culturally inclusive and sensitive (Porter, 2020).

Academic success can also be fueled by relationships on campus and outside of campus. 
Clubs and organizations create safe spaces for dialogue and interactions among the campus community, and provides opportunities for students to network and connect with peers. A majority of the participants identified as leaders in their organizations. A few also detailed involvement in organizations that promoted Black culture, visibility, and empowerment. Involvement in Black organizations is vital to identity formation among Black women, as it is developed through their involvement in extracurricular activities (Porter, 2020). Their involvement in these organizations provides them a sense of belonging and purpose. Sports activities, on the other hand, can promote better mental health (Billingsley \& Hurd, 2019). A student indicated that being involved in on-campus sports activities has led her to manage her time and provided a structure to her schedule. Thus, it can be derived that students who participate in sports can potentially exhibit good academic performance (Moody, 2011). Additionally, relationships with faculty and fellow students were beneficial for the student participants. They indicated that these on-campus relationships offer important sources of support, especially when it comes to academic success. One student mentioned that a good relationship with her professor makes it is easier to ask for clarification or guidance on classwork, while another student mentioned mentorship from professors. Furthermore, a student expressed that being in a study group also allows them to have a class-like discussion and exchange ideas, notes, and helpful study strategies. Students yearn to connect with each other as they can share experiences, lessons, and strategies that are particularly relevant in navigating their academic environments (Porter, 2020).

Family support also plays an important role in a student's overall academic success. Parents provide encouragement and advice gained from their experiences in the academic setting, providing support to help Black students decrease their levels of stress (Barnett, 2004). While students mentioned parental/familial expectations on academic achievement, excerpts obtained from the interviews show that students view it in a more positive light. Several students mentioned that "they just have to do it", meaning that they will continue on the path to academic success. Role models, in the form of parents, family members, or community members are especially important to Black women. Mentorship, interlaced with the concept of "Sankofa" which means looking to the past to inform the future (Baylor 2014), offered by these role models allow students to form positive beliefs about themselves. Additionally, when students consider themselves as role models, they are motivated to continue working hard to succeed not just academically, but also in life. This speaks to the significance of not only having a mentor but thinking of themselves as mentors to the community as well.

\section{Implications}

Factors such as previous secondary education performance, parental education, extracurricular involvement as well as a student's scholarly, social, and cultural identity play a crucial role in the student's academic life. The students' academic performance is illuminated through the lens of black feminist standpoint theory, which argues that the point of reference and unique perspective (i.e., standpoint) starts from the middle, as opposed to the margins of the story. The individuality of each student is also highlighted by looking at their 
intersectional experiences. Moreover, resiliency theory provides a lens through which the three tenets of this framework (individual, support, and familial) provide insight into the strategies and techniques that students use to deal with, and overcome the challenges posed by the academic environment. Due to the interrelation between different identities, students who received guidance and support in all three areas also had a higher probability of achieving academic success. With the data obtained and highlighted in the study, students and educators can create an effective plan of action to increase academic success and support African American women in higher education. Although the study looked into Black female students in college, it can also be adapted and applied to different student populations. The researchers hope that more attention will be given to underrepresented students to support them in reaching their full potential.

\section{Limitations}

The students in this study entered the program with a minimum GPA of 3.5. The experiences of students with a GPA lower than 3. 5 were not recorded. It is also important to note that since there were only 19 participants in the study, the sample size is not representative of the population. In addition, since randomization was not used for the selection process, the findings are not generalizable.

Another limitation is not knowing why students who qualified to participate in the study chose not to. If student availability was one of the reasons why some potential participants could not participate, it could have been further analyzed and discussed to see if it is a factor that plays a role in student academic success. Furthermore, not all 19 participants completed all interviews. There were some participants who were only interviewed once throughout the whole study. Not knowing the reasons why students did not complete the rest of their interviews, as well as having incomplete data points for some participants, was also a limitation in the study. Last but not least, the study was conducted at a university in Southern California and these findings might not be applicable to students in other regions within the United States.

\section{Conclusion}

The deficit model of thinking has been used to address underrepresented students for far too long. Instead of considering social and cultural barriers, current teaching strategies focus on students' weaknesses. This negative approach often influences the strategies employed by institutions of higher education. Thus, with the rising number of underrepresented students applying to college each year, it is crucial that these strategies are re-evaluated. Examining these issues through the lens of black feminist standpoint theory and resiliency theory would be an excellent point of departure. In contrast with the deficit model, this narrative is based on information obtained from underrepresented students and represents their unique perspectives and their journey towards academic achievement. Furthermore, this narrative puts underrepresented students into the conversation, encouraging advocates to push for 
initiatives that support student success.

\section{References}

Archer-Banks, D. A., \& Behar-Horenstein, L. S. (2012). Ogbu revisited: Unpacking high-achieving African American girls' high school experiences. Urban Education, 47(1), 198-223. https://doi.org/10.1177/0042085911427739

Balanda, M. E. (2020). Bodies without the burden: White appropriation and exploitation of Black appearance and culture. Student Publications, 857. Retrieved from https://cupola.gettysburg.edu/student_scholarship/857

Baylor, A. A. (2014). Sankofa: Traditions of mentoring among black women educators. (Doctoral Dissertation, University of Wisconsin, Milwaukee). UWM Digital Commons.

Barnett, M. (2004). A qualitative analysis of family support and interaction among black college students at an Ivy League university. The Journal of Negro Education, 73, 53-68. https://doi.org/10.2307/3211259

Billingsley, J. T., \& Hurd, N. M. (2019). Discrimination, mental health and academic performance among underrepresented college students: The role of extracurricular activities at predominantly white institutions. Social Psychology of Education, 22(2), 421-446. https://doi.org/10.1007/s11218-019-09484-8

Bliuc, A., Ellis, R. A., Goodyear, P., \& Muntele Hendres, D. (2011). Understanding student learning in context: Relationships between university students' social identity, approaches to learning, and academic performance. European Journal of Psychology of Education, 26(3), 417-433. https://doi.org/10.1007/s10212-011-0065-6

Brown, D., Blackmon, L., Rosnick, S., Griffin-Fennell, C., \& White-Johnson, B. (2017). Initial development of a gendered-racial socialization scale for African American college women. Sex Roles, 77(3), 178-193. https://doi.org/10.1007/s11199-016-0707-x

Cross, W. E. (1978). The Thomas and Cross models of psychological nigrescence: A review. Journal of Black Psychology, 5, 13-31. https://doi.org/10.1177/009579847800500102

Dennis, J., Phinney, J., \& Chuateco, L. (2006). The role of motivation, parental support, and peer support in the academic success of ethnic minority first-generation college students. Journal of College Student Development, 46(3), 223-236. https://doi.org/10.1353/csd.2005.0023

Dixon-Reeves, R. (2003). Mentoring as a Precursor to Incorporation: An Assessment of the Mentoring Experience of Recently Minted Ph.D.s. Journal of Black Studies, 34(1), 12-27. https://doi.org/10.1177/0021934703253680

Domingue, A. (2015). Our leaders are just we ourself: Black women college student leaders' experiences with oppression and sources of nourishment on a predominantly White college campus. Equity \& Excellence in Education, 48(3), 454-472. 
https://doi.org/10.1080/10665684.2015.1056713

DuBois, L. B. (2012). A qualitative inquiry on the multidimensional racial development among first-year African American college students attending a predominately White institution. The Journal of Negro Education, 81(1), 67-81. https://doi.org/10.7709/jnegroeducation.81.1.0067

Fraser, J., Shane-Simpson, C., \& Asbell-Clarke, J. (2014). Youth science identity, science learning, and gaming experiences. Computers in Human Behavior, 41, 523-532. https://doi.org/10.1016/j.chb.2014.09.048

Garmezy, N. (1991). Resilience in children's' adaptation to negative life events and stressed $\begin{array}{llll}\text { environments. } & \text { Pediatric } & \text { Annals, }\end{array}$ https://doi.org/10.3928/0090-4481-19910901-05

Hannon, C. R., Woodside, M., Pollard, B. L., \& Roman, J. (2016). The meaning of African American college women's experiences attending a predominantly White institution: A phenomenological study. Journal of College Student Development, 57(6), 652-666. https://doi.org/10.1353/csd.2016.0036

Hausmann, L., Schofield, R., \& Woods, M. (2007). Sense of belonging as a predictor of intentions to persist among African American and White first-year college students. $\begin{array}{llll}\text { Research in Higher } & \text { 8ducation, }\end{array}$ https://doi.org/10.1007/s11162-007-9052-9

Collins, P. (1989). The social construction of black feminist thought. Signs, 14, 745-773. https://doi.org/10.1086/494543

Collins, P. (2000). Black feminist thought: Knowledge, consciousness, and the politics of empowerment. New York, NY: Routledge. https://doi.org/10.4324/9780203900055

Johnson, A. J. (2008). African American female persisters in higher education: The lived experience. (Master's thesis, The University of Incarnate Word). Proquest Dissertations Publishing. (UMI No. 3306497).

Maycock, J. (1997, October 31). Wiggers with attitude: From Mailer and the Stones to Vanilla Ice and Jamiroquai, Black culture has been used and often abused by Whites. James Maycock on the long, strange history of the 'white negro'. The Guardian (London, England), 2.

Moody, B. D. (2011). Intercollegiate athletics, academic achievement, and the female, African American student athlete. Texas A \& M University-Commerce.

Obama Foundation. (n.d.). My Brother's Keeper Alliance. Retrieved from https://www.obama.org/mbka/

Porter, C. J., Green, Q., Daniels, M., \& Smola, M. (2020). Black women's socialization and identity development in college: Advancing Black feminist thought. Journal of Student Affairs Research and Practice, 57(3), 253-265. 
https://doi.org/10.1080/19496591.2019.1683021

Prince-Embury, S. (2008). Translating resiliency theory for assessment and application in schools. Canadian Journal of School Psychology, 23(1), 4-10. https://doi.org/10.1177/0829573508316560

The Center for Advanced Research on Language Acquisition. (2016). What is culture? Retrieved from https://carla.umn.edu/culture/definitions.html

The White House. (2016a). My Brother's Keeper progress report: Two years of expanding opportunities and creating pathways to success. Retrieved from https://www.whitehouse.gov/sites/whitehouse.gov/files/images/MBK-2016-Progress-Re port.pdf

The White House. (2016b). Advancing Equity for Women and Girls of Color: 2016 Updated Report. Retrieved from https://obamawhitehouse.archives.gov/sites/whitehouse.gov/files/images/2016\%20CWG \%20WGOC\%20REPORT\%20.pdf

Torres, L. (2018, Nov 17). The White Instagram influencers pretending to be Black: 'My style is my own'. The Daily Beast, 1-3

Whiting, G. W. (2006). From at risk to at promise: Developing scholar identities among Black males. Journal of Secondary Gifted Education, 17(4), 222-229. https://doi.org/10.4219/jsge-2006-407

Whiting, G. W. (2009). The Scholar Identity Institute: Guiding Darnel and other Black Males. Gifted Child Today Magazine, 32(4), 53-63. https://doi.org/10.1177/107621750903200413

White, J. W., \& Lowenthal, P. R. (2011). Minority college students and tacit "codes of power": Developing academic discourses and identities. The Review of Higher Education, 34(2), 283-318. https://doi.org/10.1353/rhe.2010.0028

Winkle-Wagner, R. (2015). Having their lives narrowed down? The state of Black women's college success. Review of Educational Research, 85(2), 171-204. https://doi.org/10.3102/0034654314551065

Women's Funding Network. (n.d.). Prosperity Together. Retrieved from https://www.womensfundingnetwork.org/what-we-do/strategy-development/prosperity-t ogether/

Xie, P. F., Osumare, H., \& Ibrahim, A. (2007). Gazing the hood: Hip-Hop as tourism attraction. Tourism Management, (2007) 28(2), 452-460. https://doi.org/10.1016/j.tourman.2006.03.009

Zacherman, A., \& Foubert, J. (2014). The relationship between engagement in cocurricular activities and academic performance: Exploring gender differences. Journal of Student Affairs Research and Practice, 51(2), 157-169. https://doi.org/10.1515/jsarp-2014-0016 


\section{Copyrights}

Copyright for this article is retained by the author(s), with first publication rights granted to the journal.

This is an open-access article distributed under the terms and conditions of the Creative Commons Attribution license (http://creativecommons.org/licenses/by/4.0/) 